Section Editor

John J. Millichap, MD

Clinical Reasoning:

\title{
A 58-year-old woman with loss of vision in her left eye
}

\section{SECTION 1}

Gary P.H. Ho, MD, PhD

Kate T. Brizzi, MD

David M. Meredith, MD, $\mathrm{PhD}$

Edward R. Laws, Jr., MD

Aaron L. Berkowitz, MD,

$\mathrm{PhD}$

Correspondence to

Dr. Ho:

gho@partners.org
A 58-year-old woman developed painless visual loss in her left eye over several days. She described the vision in her left eye as "similar to looking through a dirty screen door." She denied double vision and eye pain but reported frontal throbbing headaches associated with nausea over the preceding months. Two weeks before presentation, she had several days of nausea and vomiting that had been attributed to viral gastroenteritis.

Her medical history included hypertension and hypothyroidism secondary to ablative therapy for Graves disease.

\section{Question for consideration:}

1. What is the localization and differential diagnosis of her deficits? 


\section{SECTION 2}

Monocular visual loss may be caused by pathology in the lens (e.g., corneal ulcers and abrasions), anterior chamber (e.g., glaucoma, hyphema), retina (e.g., detachment, retinitis, infarct, hemorrhage), or optic nerve (i.e., optic neuropathy). Optic neuropathy can be inflammatory (e.g., multiple sclerosis, neuromyelitis optica spectrum disorders [NMOSDs], and neurosarcoidosis), infectious (e.g., Bartonella henselae), vascular (e.g., anterior or posterior ischemic optic neuropathy), drug- or toxin-induced (e.g., amiodarone, cyclosporine, ethambutol, methanol, toluene), neoplastic (e.g., meningioma, optic nerve glioma, lymphoma), nutritional deficiency (e.g., vitamin $B_{1}$, vitamin $B_{12}$, folate, copper), or hereditary (e.g., Leber hereditary optic neuropathy). Of these, optic neuritis and giant cell arteritis (GCA) are associated with pain (with eye movements in the former; headache in the latter), while the others are generally painless unless a compressive optic neuropathy also causes headache due to elevated intracranial pressure. Our patient's visual loss was painless, but her headache raised concern for an intracranial mass lesion or GCA, although she had no scalp tenderness or jaw claudication suggestive of GCA and erythrocyte sedimentation rate was only mildly elevated at $26 \mathrm{~mm} / \mathrm{h}$.

Examination revealed 20/25 vision in the right eye and only motion detection in the left eye, a left afferent pupillary defect, bitemporal hemianopia, swelling of the right optic disc, and pallor of the left optic disc. She had no other cranial nerve deficits and an otherwise normal neurologic examination. Additional history revealed that she had felt consistently thirsty for the past several months.

\section{Questions for consideration:}

1. How do the additional history and examination findings help guide the localization and differential diagnosis?

2. What further diagnostic tests are indicated? 


\section{SECTION 3}

The finding of ipsilateral optic nerve pallor with contralateral papilledema is consistent with Foster-Kennedy syndrome, in which a mass lesion causes ipsilateral compressive optic neuropathy (leading to disc pallor) and increased intracranial pressure (resulting in contralateral papilledema). The presence of a bitemporal hemianopia in this case suggests localization to the optic chiasm.

Her increased thirst suggests pathology in the hypothalamus or pituitary causing central diabetes insipidus. Neoplastic lesions that could affect the optic nerve, chiasm, and hypothalamus include meningioma, lymphoma, craniopharyngioma, and glioma. NMOSDs may affect the hypothalamus preferentially because of high expression of aquaporin- 4 in that location ${ }^{1}$ and could explain the patient's visual symptoms. Hypothalamic involvement can also be seen in neurosarcoid. ${ }^{2}$

MRI was performed and demonstrated a homogeneously enhancing infundibular process involving the optic chiasm, pituitary, and hypothalamus with T2/fluid-attenuated inversion recovery hyperintensity in the basal ganglia and surrounding subcortical white matter (figure, A-D).

\section{Questions for consideration:}

1. What is the differential diagnosis of these neuroimaging findings?

2. What further evaluation should be performed?
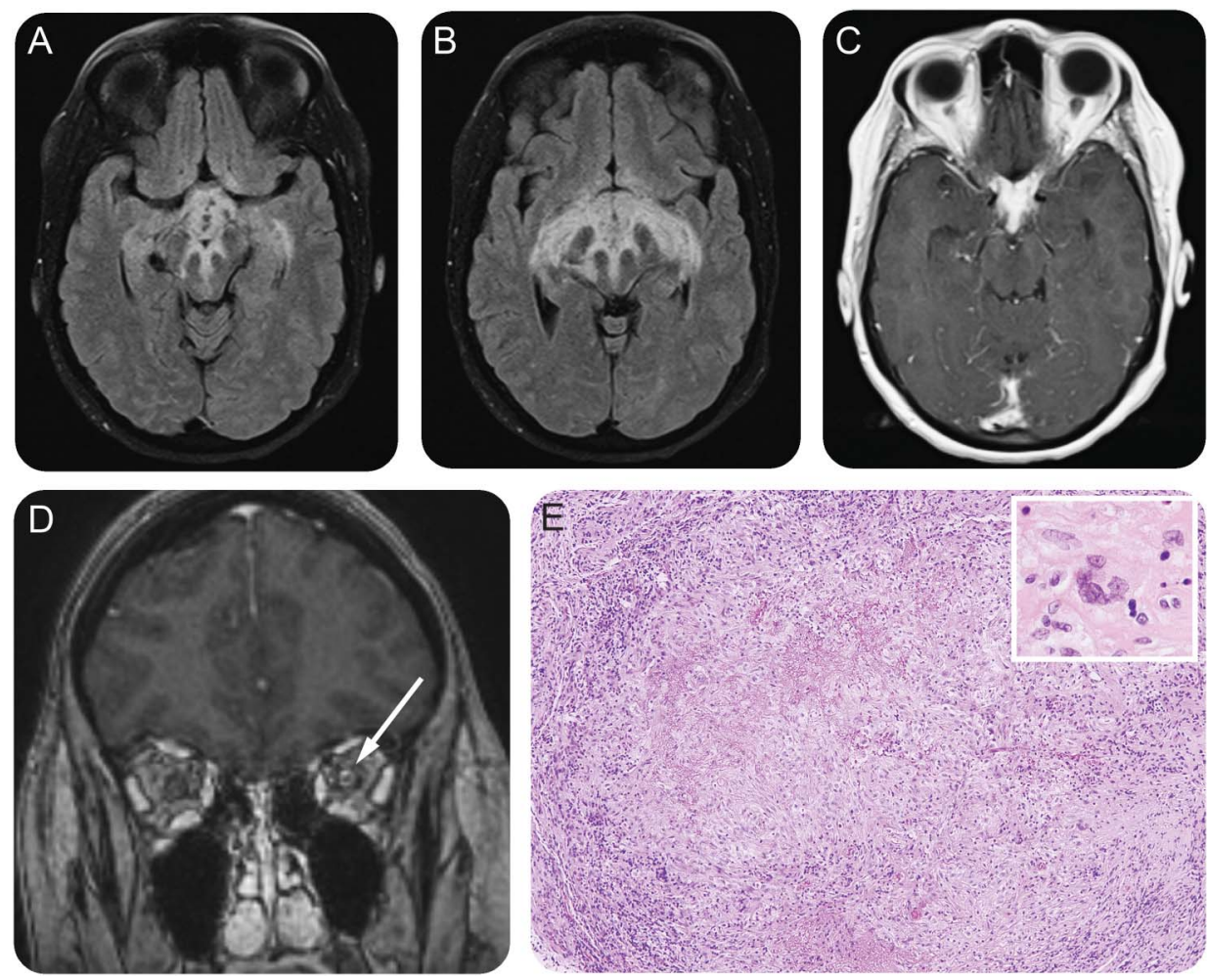

Axial fluid-attenuated inversion recovery MRIs at the level of the midbrain (A) and $5 \mathrm{~mm}$ above (B) demonstrate signal abnormality involving the hypothalamus and surrounding white matter. (C) Axial T1-weighted postcontrast MRI shows enhancement of the optic chiasm and basal leptomeninges. (D) Coronal magnetization-prepared rapid-acquisition gradient echo postcontrast MRI shows enhancement of the left optic nerve (arrow). (E) Hematoxylin \& eosin stain of a biopsy specimen from the pituitary stalk demonstrates a noncaseating granuloma with surrounding lymphocytic inflammation and reactive neuroglial tissue. (Inset) High-power magnification of a multinucleated giant cell. 


\section{SECTION 4}

The differential diagnosis for the patient's imaging findings includes NMOSD, sarcoid, lymphoma, immunoglobulin G4-related disease, Langerhans cell histiocytosis, and tuberculosis. The patient had no risk factors for tuberculosis. Her history of Graves disease puts her at increased risk for other autoimmune diseases. ${ }^{3}$

Lumbar puncture was performed, demonstrating glucose of $53 \mathrm{mg} / \mathrm{dL}$, protein of $102.6 \mathrm{mg} / \mathrm{dL}$, and 155 white blood cells/ $\mu \mathrm{L}$ with $80 \%$ lymphocytes. Cytology and flow cytometry were normal, making lymphoma less likely (although not definitively excluded after one lumbar puncture).
Serum and CSF angiotensin-converting enzyme (ACE) levels were within normal limits. PPD (purified protein derivative) testing was negative, and chest x-ray did not demonstrate hilar lymphadenopathy or other findings concerning for tuberculosis or sarcoidosis.

Further history revealed that the patient had a family history of sarcoid: 2 of her 8 siblings had sarcoid but none had neurologic involvement.

\section{Question for consideration:}

1. Given high suspicion for neurosarcoid in the setting of her family history, how can the diagnosis be further pursued? 


\section{SECTION 5}

Although elevated ACE levels may be present in sarcoid, the test has limited positive and negative predictive value. ${ }^{4}$ There is no clear normal range for CSF ACE, thus its use in the diagnosis of neurosarcoid is not well defined. ${ }^{5}$ Biopsy is generally required for a definitive diagnosis.

A PET/CT scan was performed in our patient to evaluate for hilar lymphadenopathy or areas of increased uptake outside the CNS that could be amenable to biopsy but neither was found.
Our patient therefore underwent a biopsy of the involved leptomeninges and pituitary stalk using an extended transsphenoidal approach. ${ }^{6}$ Pathology demonstrated noncaseating granulomas with negative acid-fast bacilli and methenamine silver stains, consistent with the diagnosis of sarcoid (figure, E).

\section{Question for consideration:}

1. How should the patient be treated? 


\section{SECTION 6}

Because of rapidly worsening vision, our patient was treated empirically with $1 \mathrm{~g}$ of IV methylprednisolone daily for 5 days while investigations were ongoing. Her vision improved substantially within a few days to $20 / 30$, although with a persistent deficit in the inferonasal quadrant of the left eye. She was discharged on oral prednisone $60 \mathrm{mg}$ daily. On her 6-week follow-up examination, she had 20/20 vision in her left eye and reported resolution of her headaches. A gradual taper of her steroids was initiated with plans to transition to $15 \mathrm{mg}$ daily over 8 weeks.

DISCUSSION Involvement of the nervous system in systemic sarcoid is rare, occurring in approximately $5 \%$ of all cases. ${ }^{7}$ The most common clinical manifestation is cranial neuropathy, with the facial nerve most frequently involved. ${ }^{5}$ In a case series of 30 patients with presumed neurosarcoid (43\% biopsy-proven), symptoms included headache, visual disturbance, vomiting, and ataxia $^{8} ; 11$ patients $(37 \%)$ developed optic neuropathy.

Neurosarcoid as either the initial or sole manifestation of sarcoid as in our patient is uncommon. Approximately $17 \%$ of patients with neurosarcoid have only neurologic disease and no other systemic manifestations, based on a retrospective review. ${ }^{9}$ Most patients (more than $90 \%$ ) with systemic sarcoid have lung involvement. ${ }^{4,10}$ Chest CT is more sensitive than $\mathrm{x}$-ray as a screening test for hilar lymphadenopathy. ${ }^{\mathrm{e} 1}$ Pulmonary function tests are abnormal in 65\% of patients. ${ }^{4}$

CSF in neurosarcoidosis is usually inflammatory; however, in one study, only 58\% (7/12) had increased protein, and 42\% (5/12) had a lymphocytic pleocytosis. ${ }^{\text {e2 }}$ CSF ACE level may be helpful if elevated but is neither specific nor sensitive. An increased ratio of CD4 to CD8 $\mathrm{T}$ cells in CSF has been reported in patients with neurosarcoid, ${ }^{\mathrm{e}, \mathrm{e} 4}$ with ratios $>5$ supportive of this diagnosis. ${ }^{\mathrm{e}, \mathrm{e} 6}$

The neuroimaging characteristics of neurosarcoid are highly variable. These include isolated mass lesions, diffuse intraparenchymal inflammatory lesions, and leptomeningeal lesions of the brain and/or spine. ${ }^{e 7}$ Hypothalamic involvement as was seen in our patient can occur and result in neuroendocrine dysfunction. ${ }^{\text {e8 }}$ A retrospective analysis found that $20 \%$ of patients with neurosarcoid (6/30) had pituitary or hypothalamic involvement. ${ }^{8}$

Our patient had a significant family history of sarcoid. First-degree relatives of patients with sarcoid are at higher risk of developing the disease. ${ }^{e 9} H L A-D R B 1$ and $H L A-D Q B 1$ are associated with sarcoid. ${ }^{4}$ Although ocular and hepatic sarcoid may involve the same organ systems in affected family members, this is not the case for other manifestations of sarcoid. ${ }^{\mathrm{e} 10}$

There are no clear data to determine the optimal treatment for neurosarcoid. As with systemic sarcoid, steroids are first line, with higher doses $(1-1.5 \mathrm{mg} / \mathrm{kg}$ ) often used for mass lesions or diffuse CNS involvement. For acutely evolving symptoms, a short course of IV methylprednisolone may be used followed by a steroid taper. Seventy percent of patients with neurosarcoid have a monophasic illness with sustained remission following approximately 6 months of immunosuppression. ${ }^{2}$ However, more severe cases with intracranial mass lesions or optic neuropathy often relapse as steroids are tapered, requiring prolonged immunomodulatory therapy. ${ }^{\text {e11 }}$ Mycophenolate mofetil, azathioprine, and methotrexate may be used in these settings. Recently, tumor necrosis factor $\alpha$ inhibitors such as infliximab have been used to treat refractory neurosarcoid, ${ }^{\mathrm{e} 2, \mathrm{e} 13}$ since tumor necrosis factor $\alpha$ has a role in granuloma formation. ${ }^{2,5}$ While no clinical trials have evaluated infliximab for the treatment of neurosarcoid, it has been reported to be effective in the treatment of steroid-refractory cases involving the hypothalamus, ${ }^{\text {e14 }}$ optic nerve and chiasm, ${ }^{\text {e12,e14,e15 }}$ spinal cord, ${ }^{\mathrm{e} 15, \mathrm{e} 16}$ and brain parenchyma. ${ }^{\mathrm{e}}{ }^{\mathrm{e}}$

Our patient had a relapse of blurry vision with 20/ 200 acuity and inferior and temporal restriction of visual fields in her left eye 7 weeks after her initial 6-week follow-up appointment (while on $20 \mathrm{mg}$ of prednisone in her taper). MRI showed return of nodular enhancement in the left optic nerve. She received another 3-day course of IV methylprednisolone followed by $80 \mathrm{mg}$ of oral prednisone, resulting in improvement of her visual acuity to where it had been at her prior discharge. Methotrexate was initiated and steroids were tapered, but her vision again worsened when prednisone was tapered to $25 \mathrm{mg}$ daily. The decision was therefore made to treat her with infliximab.

\section{AUTHOR CONTRIBUTIONS}

Gary P.H. Ho drafted and revised the manuscript. Kate T. Brizzi revised the manuscript. David M. Meredith revised the manuscript and created the figure for the pathologic specimen. Edward R. Laws, Jr., revised the manuscript. Aaron L. Berkowitz drafted and revised the manuscript.

\section{STUDY FUNDING}

No targeted funding reported.

\section{DISCLOSURE}

G. Ho reports, K. Brizzi, D. Meredith, and E. Laws, Jr., report no disclosures relevant to the manuscript. A. Berkowitz reports no disclosures relevant to the manuscript but receives royalties from Clinical Pathophysiology Made Ridiculously Simple (MedMaster, Inc.) and The Improvising Mind (Oxford University Press). Go to Neurology. org for full disclosures.

\section{REFERENCES}

1. Pittock SJ, Weinshenker BG, Lucchinetti CF, Wingerchuk DM, Corboy JR, Lennon VA. Neuromyelitis optica brain lesions localized at sites of high aquaporin 4 expression. Arch Neurol 2006;63:964-968.

2. Stern BJ, Aksamit A, Clifford D, Scott TF; Neurosarcoidosis Study Group. Neurologic presentations of sarcoidosis. Neurol Clin 2010;28:185-198. 
3. Boelaert K, Newby PR, Simmonds MJ, et al. Prevalence and relative risk of other autoimmune diseases in subjects with autoimmune thyroid disease. Am J Med 2010;123: 183.e1-183.e9.

4. Iannuzzi MC, Rybicki BA, Teirstein AS. Sarcoidosis. N Engl J Med 2007;357:2153-2165.

5. Krumholz A, Stern BJ. Neurologic manifestations of sarcoidosis. Handb Clin Neurol 2014;119: 305-333.

6. Kaptain GJ, Vincent DA, Sheehan JP, Laws ER. Transsphenoidal approaches for the extracapsular resection of midline suprasellar and anterior cranial base lesions. Neurosurgery 2001;49:94-100.
7. Burns TM. Neurosarcoidosis. Arch Neurol 2003;60: 1166-1168.

8. Joseph FG, Scolding NJ. Neurosarcoidosis: a study of 30 new cases. J Neurol Neurosurg Psychiatry 2009;80:297-304.

9. Chapelon C, Ziza JM, Piette JC, et al. Neurosarcoidosis: signs, course and treatment in 35 confirmed cases. Medicine 1990;69:261-276.

10. Statement on sarcoidosis. Joint Statement of the American Thoracic Society (ATS), the European Respiratory Society (ERS) and the World Association of Sarcoidosis and Other Granulomatous Disorders (WASOG) adopted by the ATS Board of Directors and by the ERS Executive Committee, February 1999. Am J Respir Crit Care Med 1999;160:736-755. 


\title{
Neurology
}

\author{
Clinical Reasoning: A 58-year-old woman with loss of vision in her left eye \\ Gary P.H. Ho, Kate T. Brizzi, David M. Meredith, et al. \\ Neurology 2016;86; e101-e107 \\ DOI 10.1212/WNL.0000000000002456
}

This information is current as of March 7, 2016

\begin{tabular}{|c|c|}
\hline $\begin{array}{l}\text { Updated Information \& } \\
\text { Services }\end{array}$ & $\begin{array}{l}\text { including high resolution figures, can be found at: } \\
\text { http://n.neurology.org/content/86/10/e101.full }\end{array}$ \\
\hline Supplementary Material & $\begin{array}{l}\text { Supplementary material can be found at: } \\
\text { http://n.neurology.org/content/suppl/2016/03/05/WNL. } 0000000000002 \\
\text { 456.DC1 }\end{array}$ \\
\hline References & $\begin{array}{l}\text { This article cites } 10 \text { articles, } 1 \text { of which you can access for free at: } \\
\text { http://n.neurology.org/content/86/10/e101.full\#ref-list-1 }\end{array}$ \\
\hline Subspecialty Collections & $\begin{array}{l}\text { This article, along with others on similar topics, appears in the } \\
\text { following collection(s): } \\
\text { Autoimmune diseases } \\
\text { http://n.neurology.org/cgi/collection/autoimmune_diseases } \\
\text { Clinical neurology examination } \\
\text { http://n.neurology.org/cgi/collection/clinical_neurology_examination } \\
\text { Neuroendocrinology } \\
\text { http://n.neurology.org/cgi/collection/neuroendocrinology } \\
\text { Optic nerve } \\
\text { http://n.neurology.org/cgi/collection/optic_nerve }\end{array}$ \\
\hline Permissions \& Licensing & $\begin{array}{l}\text { Information about reproducing this article in parts (figures,tables) or in } \\
\text { its entirety can be found online at: } \\
\text { http://www.neurology.org/about/about_the_journal\#permissions }\end{array}$ \\
\hline Reprints & $\begin{array}{l}\text { Information about ordering reprints can be found online: } \\
\mathrm{http} / / / \mathrm{n} \text {.neurology.org/subscribers/advertise }\end{array}$ \\
\hline
\end{tabular}

Updated Information \&

Supplementary Material

References

Subspecialty Collections

Neurology ${ }^{\circledR}$ is the official journal of the American Academy of Neurology. Published continuously since 1951, it is now a weekly with 48 issues per year. Copyright () 2016 American Academy of Neurology. All rights reserved. Print ISSN: 0028-3878. Online ISSN: 1526-632X.

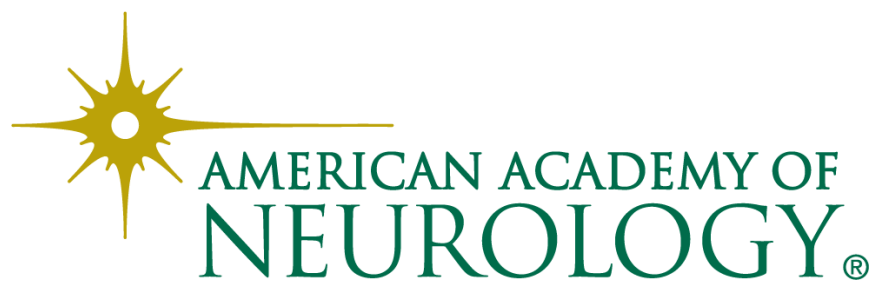

